\title{
A RELAÇÃO DIALÉTICA ENTRE A INSERÇÃO NA CARREIRA E AS CONDIÇÕES DE TRABALHO DOCENTE
}

\author{
SOLANGE CARDOSO ${ }^{1}$.
}

\begin{abstract}
${ }^{1}$ Doutoranda no Programa de Pós-graduação em Educação da Faculdade de Educação da Universidade de Brasília(PPGE/FE/UNB), membro do Grupo de Estudos e Pesquisas sobre Formação e Atuação de Professores/Pedagogos (GEPFAPe). Mestre em Educação pela Universidade Federal de Ouro Preto(2013). solangecardoso1908@gmail.com
\end{abstract}

\section{RESUMO}

Nos estudos sobre a formação e profissão docente, um dos aspectos que tem sido identificado como relevante refere-se à importância de se pensar a complexidade do início da carreira. As leituras e as discussões realizadas sobre o início da docência, momento marcado por angústias, descobertas, desafios, medos, tentativas do tipo "erro e acerto" e, ainda um momento em que o professor vive um "choque de realidades" (GARCIA, 1999; HUBERMAN, 2000; NÓVOA, 1995, PAPI E MARTINS, 2010; LIMA, 2004 E 2006; GUARNIERI, 2005; MARIANO, 2006), permitiram que nos aproximassemos dos estudos sobre essa temática e despertou-nos o interesse de melhor compreender essa etapa da carreira docente. Temos como objetivo, neste trabalho, apresentar nossas apreensões de um estudo bibliográfico que buscou compreender a relação dialética entre a inserção na carreira docente marcada por exigências pessoais, profissionais, organizacionais, contextuais, psicológicas, específicas e diferenciadas com as condições objetivas/materiais do trabalho. Os resultados deste trabalho apontaram que as características que envolvem a inserção na carreira docente, sejam elas no momento da descoberta, como o entusiasmo, ou no momento da sobrevivência, marcado pelas preocupações, angústias, medos e questionamentos nos ajudam a compreender as particularidades e os desafios que os professores estão vivenciando. Torna-se pertinente que as condições do trabalho docente também sejam olhadas e relacionadas aos demais desafios que os professores vivenciam na etapa inicial da carreira, pois elas também colaboram para que o início da docência seja sofrido, questionado e, em alguns casos, culmina na desistência da profissão, tamanho o desafio que o professor tem que enfrentar, além de se apresentar como entraves para que o professor desenvolva um bom trabalho e contribuírem para ocasionar frustações e desânimos.

Palavras-chave: Condições de trabalho; Inserção na carreira docente; Professores iniciantes

\section{THE DIALECTIC RELATIONSHIP BETWEEN CAREER INSERTION AND TEACHING WORKING CONDITIONS}

\section{ABSTRACT}


In studies on the training and teaching profession, one of the aspects that has been identified as relevant refers to the importance of thinking about the complexity of the beginning of a career. The readings and discussions carried out on the beginning of teaching, a moment marked by anxieties, discoveries, challenges, fears, attempts of the "error and success" type, and also a moment when the teacher experiences a "shock of realities" (GARCIA, 1999 ; HUBERMAN, 2000; NÓVOA, 1995, PAPI AND MARTINS, 2010; LIMA, 2004, 2006; GUARNIERI, 2005; MARIANO, 2006), allowed him to approach studies on this theme and aroused the interest to better understand this stage of his career teacher. The objective of this work is to present our apprehensions of a bibliographic study that sought to understand the dialectical relationship between insertion in the teaching career marked by personal, professional, organizational, contextual, psychological, specific and differentiated requirements with the objective / material conditions of the work. The results of this work pointed out that the characteristics that involve insertion in the teaching career, whether at the moment of discovery, such as enthusiasm, or at the moment of survival, marked by concerns, anxieties, fears and questions, help us to understand the particularities and challenges that teachers are experiencing. And that it becomes pertinent that the conditions of teaching work are also looked at and related to the other challenges that teachers experience in the initial stage of their careers, as they also collaborate so that the beginning of teaching is suffered, questioned and in some cases culminates in the giving up the profession, such is the challenge that the teacher has to face. In addition to presenting themselves as obstacles for the teacher to develop a good job and contribute to causing frustration and discouragement.

Keywords: Working conditions; Insertion in the teaching career; Beginning teachers.

\section{INTRODUÇÃO}

O crescimento quantitativo das pesquisas sobre a formação e a profissão de professores tem sido acompanhado também por um crescimento qualitativo, em que podemos observar a preocupação em abordar diferentes temas que procuram conhecer, cada vez melhor, os diversos aspectos que estão relacionados ao professor, entre este a sua inserção na carreira docente. As leituras e as discussões realizadas sobre o início da docência, momento marcado por angústias, descobertas, desafios, medos, tentativas do tipo "erro e acerto" e, ainda um momento em que o professor vive um "choque de realidades" (GARCIA, 1999; HUBERMAN, 2000; NÓVOA, 1995, PAPI E MARTINS, 2010; LIMA, 2004 E 2006; GUARNIERI, 2005; MARIANO, 2006), permitiram que nos aproximássemos dos estudos sobre essa temática e despertou o interesse de melhor compreendermos essa etapa da carreira docente.

A carreira docente, segundo Huberman (2000), desenvolve-se por meio de uma trajetória relacional, marcada historicamente, contextualmente vivenciada e construída 
individual e coletivamente. O movimento dessa trajetória é organizado por fases que evidenciam as especificidades que marcam cada momento da carreira docente. No que se refere a primeira etapa desse processo, ou seja, o momento que marca a chegada do professor à docência, evidencia-se que, para alguns, a inserção na carreira pode ocorrer de forma simples e contínua, enquanto, para outros professores, pode-se apresentar como um processo complexo e descontínuo, pois envolve elementos diversos como: a formação inicial do professor, o seu lócus de trabalho, o segmento de ensino que atuará, a forma como ocorre a socialização entre os pares (ou não ocorre), o acolhimento e o apoio da coordenação pedagógica ou a falta deste, as condições de trabalho, a temporalidade e o fato de estar iniciando na docência e estar se assumindo como professor. Alguns desses elementos podem se evidenciar mais ou todos eles podem estar presentes e impactar a etapa inicial da docência, seja de forma positiva ou negativa.

Temos como objetivo, neste trabalho, apresentar nossas apreensões de um estudo bibliográfico que buscou compreender a relação dialética entre a inserção na carreira docente marcada por exigências pessoais, profissionais, organizacionais, contextuais, psicológicas, específicas e diferenciadas com as condições objetivas/materiais do trabalho.

\section{INSERÇÃO NA CARREIRA DOCENTE E TEMPORALIDADE}

Nos estudos sobre a formação e profissão docente, um dos aspectos que tem sido identificado como relevante refere-se à importância de se pensar a complexidade do início da carreira, considerando que este é um período marcado pela passagem da condição de aluno para professor e que representa a primeira etapa da carreira docente.

Segundo Marcelo Garcia (1999), inicialmente, a preocupação centrava-se, principalmente, nos professores em formação; mas, pouco a pouco, foi aparecendo considerável literatura de pesquisa a respeito dos professores principiantes e também dos professores em exercício. Reforçando esse apontamento do Marcelo Garcia (1999), Lima (2006) também tem apontado, em seus estudos, a importância da investigação de aspectos relativos à etapa de iniciação na carreira docente, haja vista que, para a referida autora, essa etapa é a mais importante na carreira docente ao tempo em que é, também, 
a mais complexa, uma vez que é marcada por momentos de angútias e de questionamentos diante de uma fase cheia de novidades.

O início da carreira docente é desafiante, porque o sujeito deixa subitamente de ser estudante e sobre os seus ombros caí uma responsabilidade profissional cada vez maior para a qual julga não estar preparado. No entanto, os professores demonstram estar realizados ao se assumirem na profissão, responsabilizarem-se por uma turma, sentirem-se felizes e importantes por terem conseguido alcançar essa realização profissional e se empolgarem com as novidades. Para Lichtenecker (2010), o entusiasmo inicial e a exaltação, por estar, finalmente, em situação de responsabilidade, contribui para que as dificuldades encontradas sejam amenizadas.

Nos anos iniciais de inserção profissional, os professores passam por um período de tensões e aprendizagens intensivas em contextos desconhecidos, sendo cobrados a adquirir conhecimento profissional e conseguir manter um equilíbrio profissional e pessoal em um período de tempo muito breve. Lima (2006) e Marcelo Garcia (1999) compartilham que o início da docência é vivido como um período muito difícil e sofrido, sendo que ele é apontado como um dos momentos que mais causam mal-estar nos professores.

Segundo Lima(2006), a solidão tem sido apontada como uma das causas desse mal estar nos professores iniciantes, pois eles não se sentem acolhidos e vivenciam um certo tipo de abandono pela falta ou pelo pouco apoio institucional que recebem. As dificuldades também são evidenciadas, segundo a referida autora, em situações que envolvem o trato com os pais de alunos, a aprendizagem dos alunos e a manutenção da disciplina. No que se refere ao trato com pais dos alunos, a autora aponta que as reclamações feitas pelos pais no que se refere ao trabalho desenvolvido pelos professores evidencia necessidade de uma mediação institucional da escola para definir de forma clara o papel e o lugar dos pais e o apoio aos professores nas relações que envolvem as famílias e a escola. Quanto à aprendizagem dos alunos, Lima(2006) aponta que esta é a dificuldade "campeã", pois aparece com muita frequência nos relatos dos professores iniciantes. E, por fim, destaca a manutenção da disciplina, que também pode ser considerada "campeã" entre as dificuldades sentidas pelos professores iniciantes. Para a autora, essa dificuldade está relacionada ao agrupamento de alunos que cada professor recebe, ora alunos terríveis, ora alunos 
que os fazem se sentir no céu. E constata que essa situação merece ser melhor considerada nas escolas, pois tem sido comum, em algumas redes de ensino, atribuir as turmas consideradas mais difíceis ou um agrupamento de alunos com "dificuldade de aprendizagem" aos professoresiniciantes.

Para Lima (2004), nada há de se estranhar que os professores vivenciem tantas dificuldades e desafios, pois todo começo é difícil. A gravidade da questão está na forma como o processo se dá na maioria das nossas escolas, pois os próprios professores iniciantes têm de se responsabilizar individualmente por esse processo de sobrevivência, no qual o movimento, na maioria das vezes, é de disposição e de busca pessoal.

Trazemos também as contribuições de Guarnieri (2005) que direciona seus estudos para o processo de aprender a ensinar e apresenta considerações decorrentes da perspectiva dos professores iniciantes. A primeira delas é que, ao se deparar com a situação real em que se desenvolve a prática pedagógica, o professor iniciante possa abandonar ou rejeitar os conhecimentos teórico-acadêmicos que adquiriu na formação inicial pela dificuldade em colocá-los em prática. Essa atitude contribui para que o professor incorpore a cultura existente na escola, de forma passiva, resistindo às mudanças e evitando os conflitos pela adesão a um modelo aceito e inquestionável. A segunda implicação consiste no fato de o professor iniciante ter uma concepção teórica definida e, assim, tentar aplicá-la de uma forma direta em sua prática. Essa atitude pode levá-lo a não perceber as limitações que o conhecimento teórico possui, fazendo com que passe a julgar a prática pedagógica da escola como inadequada, ultrapassada e impeditiva para a realização de ações mais conscientes. Além disso, essa atitude pode fazer ainda com que o professor considere a prática e a cultura escolar como tradicionais, pois ele não saberá resolver determinados problemas de maneira coerente com a sua concepção teórica. Assim, essa constatação poderá levá-lo a adotar as formas de agir dos professores que já estão na escola, provocando uma frustração e um conflito para si próprio. A terceira implicação consiste no fato de que o professor iniciante, embora possa criticar a cultura da escola e as práticas docentes, seja capaz de perceber os aspectos positivos e esses podem passar a constituir parâmetros para que ele perceba os limites e os problemas da sua prática e das concepções teóricas que ele já tinha incorporado. 
Para melhor situarmos a etapa inicial da carreira docente, recorremos ao Ciclo de Vida dos Professores, desenvolvido por Huberman (2000). Esse ciclo apresenta as características presentes em cada fase do desenvolvimento e possibilita compreendermos o quanto a carreira docente é marcada por características próprias que a difere em cada etapa. Para Huberman (2000), a carreira é um processo contínuo e não uma série sucessiva de acontecimentos e é marcada pela não uniformidade dos sentimentos vivenciados pelos professores nas etapas, pois suas definições apresentam um entendimento mais generalizante sobre elas. Assim, Huberman (2000) organizou as etapas do ciclo de vida dos professores considerando a temporalidade da carreira e as características recorrentes observadas em cada uma, como mostra o Quadro 1, elaborado pelo autor.

Quadro 1 - Modelo síntese elaborado por Michael Huberman

\begin{tabular}{|c|c|}
\hline Anos da carreira & Fases / Temas da Carreira \\
\hline $1-3$ & $\begin{array}{c}\text { Entrada, Tateamento } \\
\downarrow \\
\text { Estabilização, consolidação do repertório } \\
\text { pedagógico }\end{array}$ \\
\hline $25-35$ & $\begin{array}{l}\text { Diversificação } \\
\text { Serenidade, } \\
\text { Distanciamento afetivo }\end{array}$ \\
\hline $35-40$ & $\begin{array}{c}\text { Desinvestimento } \\
\text { (sereno ou amargo) }\end{array}$ \\
\hline
\end{tabular}

Fonte: Huberman (2000), adaptado pela autora. 
Para o referido autor, a fase de entrada na carreira ou a fase do tateamento corresponde aos três primeiros anos da docência. Essa fase é caracterizada pela "sobrevivência" e pela “descoberta". A "sobrevivência" relaciona-se com

[...] o "tatear constante, a preocupação consigo próprio, a distância entre os ideais e as realidades cotidianas da sala de aula, a fragmentação do trabalho, a dificuldade em fazer face, simultaneamente, à relação pedagógica e à transmissão de conhecimentos, a oscilação entre relações demasiado íntimas e demasiado distantes, dificuldades com alunos que criam problemas, com material didático inadequado etc. (HUBERMAN, 2000, p. 39).

Já o aspecto da "descoberta", relaciona-se ao entusiasmo do professor diante das novidades que vão sendo desvendadas a cada dia em sua profissão e que estão atreladas à experiência de se sentir responsável por uma turma ou por se sentir como um membro de um grupo. O autor destaca ainda que esses dois aspectos podem ser vividos em paralelo, sendo que a descoberta permite suportar o aspecto da sobrevivência. A fase da estabilização corresponde ao período entre 4 a 6 anos de carreira, caracterizada pelo comprometimento definitivo na docência e, ainda, como uma fase de tomada de responsabilidades. A fase da diversificação e a fase do questionamento ocorrem no mesmo período, qual seja entre 7 a 25 anos de carreira. No entanto, a primeira é marcada pela quebra da rigidez pedagógica (quando o professor começa a fazer experimentações) enquanto a segunda é caracterizada pelas dúvidas quanto à carreira e quanto à profissão. Já no período entre 25 a 35 anos de carreira, ocorre a fase da serenidade e distanciamento afetivo, identificadas por características que vão ao encontro do nome que a define. Nesse mesmo período, observa-se, também, a fase do conservadorismo, marcada pelo distanciamento das lamentações frente à profissão. Por último, a fase do desinvestimento, que ocorre entre 35 a 40 anos de docência, quando os professores se afastam da profissão e dedicam o seu tempo mais a si próprios.

Huberman (2000) ressalta que não há sequências universais, pois o seu desenvolvimento se relaciona com as condições sociais e com o período histórico; e ainda que cada etapa prepara a seguinte, mas sem determinar a ordem da fase que virá na sequência. As características apontadas por Huberman (2000) ajudam-nos a compreender as ações dos professores em cada fase da carreira docente, mas destacamos, neste trabalho, a fase inicial, denominada por ele " entrada". E ressaltamos que o autor contribui para pensarmos que, em cada etapa, devemos considerar as particularidades, os sentimentos, os dilemas e os desafios que os professores estão 
vivenciando e assim propormos ações, programas e políticas que contribuam para acolher e auxiliar o professor nesta etapa inicial da sua carreira.

Esse período inicial da carreira docente - inserção na carreira docente apresenta características e necessidades próprias, marcada por um misto de sentimentos e comportamentos, no qual podemos observar que os professores apresentam uma grande disponibilidade para aprender e ensinar e ficam "encantados" por estarem assumindo a sala de aula. Contudo, eles vivenciam o sentimento de angústia e de medo diante do novo, bem como enfrentam a dificuldade em manter a disciplina dos alunos, os problemas relacionados com o processo de distribuição de turmas, a preocupação consigo mesmo em relação às suas habilidades, capacidades e competências, a recepção e a socialização com os pares. E, somado a tudo isso, muitos ainda vivenciam o desafio de "sobreviver" e desenvolver o seu trabalho em ambientes que oferecem más condições de trabalho.

As pesquisas têm mostrado que os professores entendem essa fase inicial da docência como uma etapa de intensa aprendizagem e de grande importância, mas consideram-na muito dolorosa, uma vez que vem acompanhada de sentimentos como: solidão, vontade de desistir, cansaço, nervosismo, sensação de incompetência, exaustão, desilusão, incapacidade, frustração e desgaste físico e emocional. E somado a todos esses fatores que se apresentam como desafios para os professores iniciantes, consideramos que as más condições de trabalho podem agravar ainda mais esses sentimentos negativos e contribuir para que o professor questione a sua profissão, não invista em sua carreira ou até mesmo desista da docência.

Diante disso, apresentamos no tópico a seguir considerações iniciais sobre as definições e compreensões sobre as condições de trabalho docente. Tal proposta tem o intuito de considerarmos e olharmos para as condições de trabalho como um elemento que também contribui para tornar a inserção da carreira um momento sofrido, logo torna-se um problema dos professores iniciantes que, assim como os demais, precisa ser considerados para que se possa buscar alternativas para amenizar e superar essas dificuldades. 


\section{CONDIÇÕES DE TRABALHO DOCENTE: DESAFIO PARA O PROFESSOR INICIANTE}

Segundo Kuenzer e Caldas (2009), entende-se por condições do trabalho docente o conjunto de recursos que possibilita uma melhor realização do trabalho educativo e que envolve as condições físicas das escolas, a relação com os pares, a relação com os alunos, o número de alunos por turma, os recursos didáticos disponíveis, o sistema burocrático determinado aos docentes, o controle externo sobre o trabalho docente e as especificidades que marcam o segmento de ensino no qual o professor atua, bem como os serviços de apoio aos educadores e à escola. A falta de boas condições de trabalho acentua sentimentos negativos a carreira, ressoa sobre o desempenho do professor e, consequentemente, sobre os resultados que se espera dele no que se refere à aprendizagem dos alunos. No que se refere às condições de trabalho no início da carreira, estas se destacam e tem uma importância ainda maior, pois os professores iniciantes, em sua maioria, sentem-se inseguros, sem orientação, angustiados e tensos diante da novidade de "subir no palco" da docência e assumirem sozinhos a sala de aula. E, se somado a todos esses sentimentos que os afligem, eles ainda tiverem que lidar com as más condições de trabalho, a inserção na carreira pode levá-los a pensar em desistir da profissão ou contribuir para que ele não invista em sua carreira. Dessa forma, teremos um professor em início de carreira já em declínio, por não encontrar boas condições de trabalho.

A forma que o trabalho docente está organizado nas escolas acarretam em precarização e intensificação do trabalho. Por precarização, consideram-se as más condições materiais para exercer o trabalho docente, como: turmas numerosas de alunos, salários baixos, falta de segurança, violência em seus vários formatos, falta de materiais didáticos e salas de aula com mobiliário em mau estado de conservação. Segundo Marin (2010), o termo "precarização" tem sua origem nas Ciências Sociais, a partir das formulações de Pochmann (1999). Esse autor, considerando a expansão do neoliberalismo, sobretudo a partir da década de 1990, identifica que surgem mudanças no mercado de trabalho como: redução de custos no trabalho, modificações nos direitos dos trabalhadores, nos movimentos sindicais e nas jornadas de trabalho. Assim, a precarização do trabalho docente, segundo Marin (2010), é uma expressão polissêmica, 
pois pode ser compreendida tanto pelos significados/caracterizadores quanto pelas consequências de sua existência.

Por intensificação do trabalho, compreende-se a energia que é despendida psíquica e fisicamente no trabalho e também a perda de energia emocional, no cumprimento da realização de obrigações que chegam em múltiplas instâncias como o preenchimento dos diários, relatórios individuais de aluno, ocorrências indisciplinares, planejamentos, reuniões pedagógicas, etc. Segundo Dal Rosso (2008), conceituar a intensificação do trabalho implica em compreender que esta se origina do processo de trabalhar que, por conseguinte, relaciona ao grau de dispêndio de energia realizado pelos trabalhadores no ato de realizar suas atividades concretas. Significa trabalhar de forma mais densa, com um gasto de energia pessoal maior para dar conta de cargas adicionais de trabalho ou de tarefas mais complexas que resultam em desgaste e fadiga mental, emocional, fisiológica e relacional. Além disso, devem-se considerar outros elementos como: as condições de trabalho, as relações de cooperação entre os próprios trabalhadores, a transmissão e/ou troca de conhecimento entre eles e as relações familiares, grupais e societais, que estão presentes no dia a dia do trabalhador e que refletem em seu espaço do trabalho, seja como potencialidade ou como problema. Vale ressaltar que a intensificação não está relacionada ao volume de trabalho, mas a uma exaustão, pois outros profissionais poderão ter o mesmo volume de trabalho, mas não se desgastarão física e emocionalmente, por encontrarem melhores condições de trabalho. A precarização e a intensificação do trabalho contribuem assim para que o trabalho pedagógico não encontre, segundo acreditamos, as condições mínimas necessárias para ser bem desenvolvido, contribuindo para que o professor questione e/ou não invista na sua carreira e sinta a sua entrada na carreira docente de forma sofrida.

\section{CONSIDERAÇÕES FINAIS}

Os resultados deste trabalho apontaram que as características que envolvem a inserção na carreira docente, sejam elas no momento da descoberta, como o entusiasmo, ou no momento da sobrevivência, marcado pelas preocupações, angústias, medos e questionamentos nos ajudam a compreender as particularidades e os desafios que os professores estão vivenciando. E que se torna pertinente que as condições do trabalho 
docente também sejam olhadas e relacionadas aos demais desafios que os professores vivenciam na etapa inicial da carreira, pois elas também colaboram para que o início da docência seja sofrido, questionado e, em alguns casos, culmine na desistência da profissão, tamanho o desafio que o professor tem que enfrentar. Além de se apresentarem como entraves para que o professor desenvolva um bom trabalho e contribuírem para ocasionar frustações e desânimos.

Apontamos que o acompanhamento/acolhimento de forma organizada junto ao professor iniciante e boas condições de trabalho podem contribuir para amenizar a complexidade dos primeiros anos da docência e ajudar a torná-la menos sofrida. Para que isso aconteça, torna-se necessário pensar na importância da mediação de programas e políticas que se comprometam com o apoio ao professor iniciante, a fim de ajudá-los a acionar os seus saberes e transformá-los em possibilidades dentro da sua carreira docente. Salientamos ainda que, no início da docência, os professores não deveriam se responsabilizar sozinhos por pensar a sua prática e, nem mesmo, se sentir como os únicos responsáveis pelas aprendizagens que ocorrem nessa fase do seu trabalho profissional.

\section{REFERÊNCIAS}

DAL ROSSO, S. Mais Trabalho! a intensidade do labor na sociedade contemporânea. São Paulo : Boitempo, 2008. 206 p.

GUARNIERI, M. R. (Org.). Aprendendo a ensinar: o caminho nada suave da docência. 2. ed. Campinas, SP: Autores Associados; Araraquara, SP: Programa de Pósgraduação em Educação Escolar da Faculdade de Ciências e Letras da UNESP, 2005. (Coleção polêmicas do nosso tempo).

HUBERMAN, M. O ciclo de vida profissional dos professores. In: NÓVOA, A. (Org.). Vidas de professores. 2. ed. Porto: Porto, 2000. p.31-61.

KUENZER, A Z.; CALDAS, A: Trabalho docente: comprometimento e desistência. In: FIDALGO, Fernando, OLIVEIRA, Maria Auxiliadora M., FIDALGO, Nara Luciene ROCHA (Orgs): A Intensificação do Trabalho Docente: tecnologias e produtividades. Campinas, SP: Papirus, 2009.

LICHTENECKER, M. S. Desenvolvimento profissional de professores principiantes e os movimentos para a assunção da profissão docente. 2010. 252f. Dissertação 
(Mestrado em Educação) - Universidade Federal de Santa Maria, Santa Maria, RS, 2010 .

LIMA, E.F A construção do início da docência: reflexões a partir de pesquisas brasileiras. 2004. Disponível em: 〈http://coralx.ufsm.br/revce/revce/2004/02/a6.htm>. Acesso em: 27. nov. 2011.

LIMA, E. F. de. (Org.). Sobrevivências no início da docência. Brasília: Líber Livro Editora, 2006.

MARCELO GARCIA, C. Formação de professores. Para uma mudança educativa. Porto: Porto Editora, 1999.

MARCELO GARCIA, C. Desenvolvimento Profissional: passado e futuro. Sísifo Revista das Ciências da Educação, n. 08, p.7-22, jan/abr.2009.

MARIANO, A. L. S. Aprendendo a ser professor no início da carreira: um olhar a partir da ANPEd. 2005. Disponível em: 〈http://www.ANPEd.org.br〉. Acesso em: 10 jan. 2012.

MARIN, A.J. Precarização do trabalho docente. In:OLIVEIRA, D.A.; DUARTE, A.M.C.; VIEIRA, L.M.F. DICIONÁRIO: trabalho, profissão e condição docente. Belo Horizonte: UFMG/Faculdade de Educação, 2010. Disponível em: http://www.gestrado.net.br/?pg=dicionario-verbetes\&id=331. Acesso em: 26 jan. 2018

NÓVOA, A. A formação de professores e profissão docente. In: Os professores e a sua formação. 2. ed. Lisboa: Dom Quixote,1995.

PAPI, S. O.; MARTINS, P. L. As pesquisas sobre professores iniciantes: algumas aproximações. Educação em Revista, Belo Horizonte, v. 26, n. 3, p. 39-56, dez. 2010. 